\title{
Research on Academic Procrastination among OEC Students
}

\author{
Yun Feng ${ }^{1, a^{*}}$, Xiaojia Huang ${ }^{1, b}$ and Shizhu Liu ${ }^{2, c}$ \\ ${ }^{1}$ Department of Pharmacology, School of Medicine, Jiangsu University, Zhenjiang, Jiangsu \\ 212013, China \\ ${ }^{2}$ School of Management, Jiangsu University, Zhenjiang, Jiangsu 212013, China \\ afengyun76@126.com, bharold1980@163.com, 'liusz1188@126.com
}

Keywords: Overseas students; Academic Procrastination; Psychological Perspective

\begin{abstract}
Procrastination is a behavior that evades the task. The two key features of procrastination are postponement and irrationality. Procrastination is often manifested by the use of non-urgent tasks instead of urgent ones, with simple and happy work instead of a difficult one. Sometimes procrastinators can delay the task to the "last second" before the cut-off date. Procrastination can lead to mental illnesses such as guilt, discontent, depression, and self-doubt. There is widespread delay in the time spent by College students, and it is estimated that most of College students have procrastination; allmost all of them think they are procrastinators. Delay has become an important factor affecting the mental health of College students. In this article, we focus on young people, including College students, and try to understand procrastination from psychological perspective, the causes of the delay, as well as the mechanism and management of procrastination, so as to help young people prevent such behavior, especially College students' academic procrastination.
\end{abstract}

\section{Introduction}

Procrastination is a voluntary delay in the completion of a task if the expected delay leads to adverse consequences. Procrastination can involve anything in life, such as cleaning rooms, repairing equipment, seeing a doctor, submitting a report, completing an academic mission, or resolving disputes with colleagues, etc. [1] Delay is not necessarily procrastination. "Defer" and "irrational" are two key points of procrastination, which is to say if there is a reasonable reason; delay is not necessarily procrastination, even if a task is delayed. Gregory Schraw and Steel et al. in 2007 proposed that the three characteristics of academic procrastination are: no output, no need, and delay. [2, 3]

Academic procrastination has become an important problem associated with a high incidence of ivory tower. Studies in the eighties and nineties of the last century found that $52 \%$ of the students surveyed showed moderate-to-high non self-controlled delays. Forty-six percent, $7.6 \%$ and $30.1 \%$ of students reported that in their paper writing, exams, and weekly readings, they "always" or "almost always" delay. At present, most universities offer free and fast twenty-four-hour Internet service. But, many College students lack effective time management skills in using the Internet. They often spend their time on simple and interesting, but irrational things, leading to academic procrastination, which has become a major problem in College. There are as many as 55-65\% of people who wish to reduce procrastination during reading, examination, and paper writing. Nearly a quarter of the students reported that they had become obsessed by their habit of delaying. Due to procrastination, the procrastinator may have psychological problems such as guilt, discontent, depression, and self-doubt. [4] Academic procrastinations not only cause psychological problems, but can also lead to serious moral problems for students. A large-scale follow-up study conducted with German College students in 2014 showed that academic procrastination were positively correlated with the frequency of seven different forms of academic misconduct. [5]

This paper summarizes the research on the academic procrastination among College students in the past two decades, in order to understand the phenomenon of procrastination and its solution. 


\section{The Performance of the Procrastinators}

Active and passive procrastinators. In 2005, a study showed that there were two kinds of procrastination: one is the traditional procrastination, called passive procrastination, and the other is proactive procrastination, in which a person finds the pleasure of completing any task only under pressure. The latter is called, positive procrastination. The main difference between these two types is that the proactive procrastinators perceive and control time far more than the passive procrastinators. [6] It is surprising, however, that the level of academic performance of active and passive procrastinators is similar. $[7,8]$ It is noted that no matter what kind of procrastination it might be, the harm caused is similar for both types.

Eveningness. Procrastination is related to human responsibility and impulsivity. The phenomenon of procrastination decreases with age. [3] It is widely known that throughout the life cycle, people's sense of responsibility gradually increases, and a physiological rhythm of morningness is gradually developed from eveningness. Although the cause of procrastination and late sleep is unclear, there is indeed a relationship between them: the more people delay their night sleep, the more likely they develop procrastination. However, in addition to age, there is still an unknown relationship between procrastination and night sleep, which has not been fully elucidated. [9]

Fear of the future. Undergraduate survey found that procrastinators pay less attention to the future, and instead are more concerned about what they see now. [6] There is a high positive correlation between attitude and procrastination in life and fatalism. [10] This finding is consistent with previous studies on procrastination and depression. Fear of failure and success is also related to student procrastination.

Worse grades. In 1997, Tice et al reported that more than one-third of the final exam results could be attributed to procrastination. The grades of procrastinators are worse than those of non-procrastinators. The negative correlation between procrastination and academic performance in a number of studies is consistent and repeatable. In 2006, Howell et al found that the procrastinator' s self-judgment was significantly and negatively correlated with the score, even though the procrastination scores obtained with the universal approach were independent of the results. [11]

Mental health disorders. Procrastination may be the symptoms of psychological disorders, causing great damage to daily life. Procrastinators may have many neuropsychiatric disorders such as depression, irrational behavior, low self-esteem, anxiety, attention deficit, ADHD, guilt, and stress. Procrastination is a sense of powerlessness, maximizing pain, failure, and vice versa. When a deadline is still far, procrastinators are less likely than non-procrastinators to suffer from stress and physical illness. However, as the deadline approaches, procrastinators report more stress and physical illness. In general, procrastinators suffer more stress and health problems. [12] Therefore, for people with procrastination, it is necessary to see a trained psychiatrist to check for potential mental health problems.

\section{Procrastination-Related Psychological Factors}

Lack of motivation. There is scarcity of motivation, and scientists have put forward the theory of time motivation, which integrates the motivational theory of predecessors and the procrastination meta-analysis results, and summarizes the key predictors of expectation, value, and impulse delay Equation. [3, 13] Motivation theory shows that the individual's motivation can be expressed by the following formula (Figure 1). The greater the individual' s motivation the less easy the individual will delay, and vice versa.

$$
\text { Motivation }=\frac{\text { Expectancy } \times \text { Value }}{1+\text { Impulsiveness } \times \text { Delay }}
$$

Figure.1 Task Motivation Formula 
Motivation: the desire for specific results; Self-efficacy: the probability of success; value: the reward associated with the results; impulse: the sensitivity of the delay; delay: the time required to effect the plan.

The limitation of the above formula is that the effect of time on the motivation is not taken into account. Time motivation theory adds time factor to the above motivation theory, which can be explained by the example of student academic procrastination: a student who will be taking a final exam in a month' $\mathrm{s}$ time has two choices; learning and socializing. Students who like to socialize, but want to achieve good grades must choose to learn instead. Initially, the motivation for learning is lower than that of socializing. However, as the study period decreases from a few weeks to a few days, learning motivation would gradually increase beyond social motivation.

The principle of happiness in procrastination. The principle of happiness means avoiding negative emotions and delaying stressful tasks, which may be the cause of the procrastination. [14] This assumption implies that stress is another incentive for procrastination. Psychologists believe that this stress-related procrastination is the mechanism by which tasks and decisions are related to the occurrence of anxiety. [15]

Perfectionism leads to procrastination. Perfectionists tend to adversely evaluate their performance. [16] The perfectionists are very much afraid of being judged by others. They have a high degree of social anxiety, and their mood is also repeatedly low. Traditionally, procrastination has been associated with perfectionism. However, perfectionism can be divided into two types: adaptive and maladaptive perfectionism. The maladaptive perfectionist is more likely to procrastinate and worry than the adaptive perfectionist. Regression analysis found that, besides the perfectionists who undergo clinical counseling, mild-to-moderate perfectionists usually procrastinate only slightly more than others. [3]

Coping responses. Procrastinators tend to take negative measures such as being evasive or emotional, rather than aiming at the task to solve the problem. [17] Emotion and avoidance provide immediate pleasure to procrastinators, which can reduce stress caused by procrastination. This is very attractive to impulsive procrastinators. The following table lists several emotional responses of procrastinators to tasks (Table 1) [18].

Table.1 The emotional responses of procrastinators to the tasks

\begin{aligned} & \hline Coping responses examples \\ & Avoidance $\begin{array}{l}\text { Getting away from the scene or location of the mission (for example, graduate } \\ \text { students avoid entering the laboratory) }\end{array} \\ &$ Denial To pretend that the current task is more important than the task being escaped from. \\ & Diversion of Getting oneself immersed in other things that are immediately met in order to prevent \\ & attention $\begin{array}{l}\text { awareness of tasks (such as immersing oneself in video games or surfing the Internet) } \\ \text { To compare ones own life with someone whose life is worse (e.g. "Yes, I got a C- in } \\ \text { the course, but I didn't perform as bad as the others.") }\end{array} \\ &$ Balance $\begin{array}{l}\text { Emphasizing one's satisfaction that someone else has achieved in the meantime, } \\ \text { instead of doing something else. }\end{array} \\ &$ Criticism $\begin{array}{l}\text { Attributing the reason of procrastination to external factors beyond their control (e.g. } \\ \text { "I do not intend to delay, but this is too hard") }\end{array} \\ &$ Mockery Criticize others in a rash and mocking manner in their efforts to achieve their goals. \\ & \hline\end{aligned}

\section{Solutions to Procrastination}

Spontaneous solution: Student syndrome. "Students Syndrome" means that, students are fully committed to completing the task when the deadline is approaching. A 2002 study showed that many students were aware of their delays and set a due date by the deadline. Setting an early due date will give students a better performance. Studies have shown that after the beginning of the practice, student' $s$ engagement a week before the deadline reaches five times that of the sum of the first three 
weeks. $[19,20]$ Academic procrastinators tend to do most of their work in the last week before the deadline.

Strict schedules and structured procrastination. In fact, there is no specific way to develop a plan to follow for the treatment of procrastination. The way to develop a strict schedule for a task may not apply to everyone. Performing tasks with a flexible schedule may be better than using a rigid schedule. [21] The key to overcoming procrastination is to better manage the time, including awareness and use of "power hours". The good way is to follow the natural circadian rhythm to achieve the most productive work. To establish the reality of the goal, it is essential to cherish any "small success". If we know how to balance excellent work with perfect relaxation, our lives will become happier, healthier, and more effective. [21]

Procrastination is not laziness just those procrastinators often tend to spend time outside tasks, which they consider important. John Perry, in the article, "structured procrastination", proposed a "deceit" approach to solving the problem of procrastination. This approach uses the Pyramid scheme, which indicates the importance of the task in order for procrastinators to accomplish the unpleasant tasks at hand. [22] The fundamental meaning of structured procrastination is to make a list of the tasks that must be done, based on the actual situation. The list of tasks is sorted by importance. Very urgent and important tasks are placed at the top and the less important tasks can be placed at the lower level. We can do the tasks at the lower level to avoid the more important ones at the top. If procrastinators are able to take advantage of the deception, they can become productive people.

Reduce procrastination from childhood. The procrastination shown by young people in the university may have begun from childhood. Meta-cognitive skills such as goal setting, breakdown of tasks, and monitoring of progress, can all be taught by parents to children, and the children can learn these skills. Psychologists say that this is not just to help children develop willpower, but also it is the process of developing their skills. Skills and willpower combine to help children succeed in self-supervision. Here are the ways to guide children to avoid procrastination (Table 2):

Table.2 A guide for children to avoid procrastination

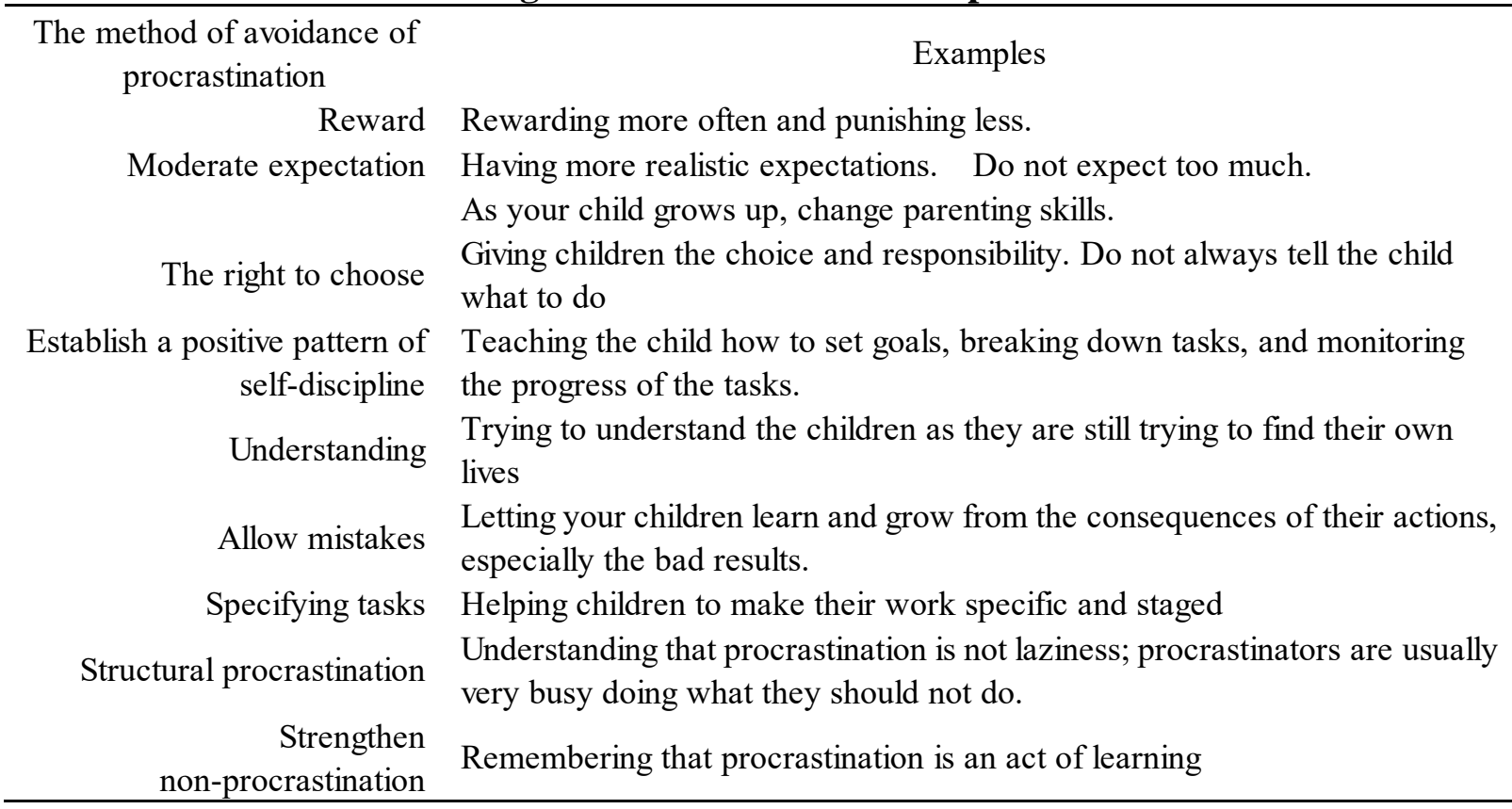

Management of College students' procrastination. If the problem of procrastination can be resolved in childhood, procrastination treatment during College is less important. But psychologist, William J. Knaus, expects that 90 percent of College students procrastinate. Twenty-five percent of these students are chronic procrastinators. Usually these people will eventually drop out of school. [23, 24] In order to overcome procrastination in adults, especially among College students, the following points should be taken into consideration (Table 3): 
Table.3 The Countermeasures to College Students' Procrastination

\begin{tabular}{|c|c|}
\hline Countermeasures & Examples \\
\hline $\begin{array}{r}\text { Solve their own } \\
\text { related problems }\end{array}$ & $\begin{array}{l}\text { Seeking ways to eliminate such things as fear, anxiety and lack of concentration, poor } \\
\text { time management, indecisiveness, and perfectionism. }\end{array}$ \\
\hline Self-assessment & $\begin{array}{l}\text { Paying attention to the habits and ideas that lead to procrastination. Assess your goals, } \\
\text { strengths, weaknesses, and priorities. }\end{array}$ \\
\hline Set goals & Setting realistic goals, and actively linking specific and meaningful goals and tasks. \\
\hline Adjust daily life & Readjusting the time schedule of daily life \\
\hline $\begin{array}{l}\text { Change the } \\
\text { environment }\end{array}$ & $\begin{array}{l}\text { Eliminating or minimizing noise or interference; do your utmost best; reduce } \\
\text { daydreaming }\end{array}$ \\
\hline Follow the priority & Following your priorities \\
\hline Positive motivation & $\begin{array}{l}\text { Motivating yourself through pleasant activities, social interactions, and constructive } \\
\text { interests. }\end{array}$ \\
\hline Small success & $\begin{array}{l}\text { Solving small problems in a short time, rather than trying to solve the whole thing } \\
\text { immediately, and then getting yourself intimidated by it. }\end{array}$ \\
\hline $\begin{array}{r}\text { Strengthen the } \\
\text { results }\end{array}$ & $\begin{array}{l}\text { To prevent relapse of procrastination, reinforce your preset aims based on needs and } \\
\text { allow yourself to be rewarded for accomplishing tasks. }\end{array}$ \\
\hline
\end{tabular}

The above techniques are not valid for serious procrastinators. Like other addicts, serious procrastinators are also incompetent, and cannot overcome their own problems. Because of the external intervention, procrastinators can get immediate returns, and their symptoms often change. For example, if someone else can regularly accompany the procrastinator to complete problematic tasks, or observe him as he does things, the incapacity of the procrastinator will decline rapidly; self-confidence will reappear, and the procrastinating habit will be changed. [25]

\section{Acknowledgements}

Thanks for the support from below funds:

1. 2016 China Ministry of Education awarded the second batch of "Top Brand Curricula" of English teaching program-Pharmacology

2. 2015 Jiangsu Province awarded the excellent curricula of Englishi teaching program for overseas students-Pharmacology

3. The key project of education reform program in Jiangsu University in 2015, item No. 2015JGZD027

4. 2012 Jiangsu Province Postdoc Fund 1202041C

\section{References}

[1] Solomon, Laura J.,Rothblum, Esther D. Academic procrastination: Frequency and cognitive-behavioral correlates. Journal of Counseling Psychology 1984;31:503-509

[2] Schraw GW, Theresa; Olafson, Lori. Doing the Things We Do: A Grounded Theory of Academic Procrastination. Journal of Educational Psychology 2007;99:14.

[3] Steel P. The nature of procrastination: a meta-analytic and theoretical review of quintessential self-regulatory failure. Psychological bulletin 2007;133:65-94.

[4] Beswick G, Rothblum ED, Mann L. Psychological antecedents of student procrastination. Australian psychologist 1988;23:207-217.

[5] Patrzek JS, S.; van Veen, F.; Grunschel, C.; Fries, S. . Investigating the Effect of Academic Procrastination on the Frequency and Variety of Academic Misconduct: A Panel Study". Studies in Higher Education. 2014:16. 
[6] Chu AH, Choi JN. Rethinking procrastination: positive effects of "active" procrastination behavior on attitudes and performance. J Soc Psychol 2005;145:245-264.

[7] Hsin Chun Chu ANC, Jin. Rethinking Procrastination: Positive Effects of "Active" Procrastination Behavior on Attitudes and Performance. The Journal of Social Psychology;145:10.

[8] Zhang W, Wang X, Feng T. Identifying the Neural Substrates of Procrastination: a Resting-State fMRI Study. Scientific reports 2016;6:33203.

[9] Beutel ME, Klein EM, Aufenanger S, et al. Procrastination, Distress and Life Satisfaction across the Age Range - A German Representative Community Study. PloS one 2016;11:e0148054.

[10] Ferrari JR, Díaz-Morales JF Procrastination: Different time orientations reflect different motives. Journal of Research in Personality 2007; 707:714.

[11] Howell AJW, D. C.; Powell, R. A.; Buro, K. Academic Procrastination: The Pattern and Correlates of Behavioral Postponement. Personality and Individual Differences 2006;40:21.

[12] Pychyl TAL, J. M.; Thibodeau, R.; Blunt, A. "Five Days of Emotion: An Experience Sampling Study of Undergraduate Student Procrastination (special issue). Journal of Social Behavior and Personality 2000;15:5.

[13] Durakiewicz T. A Universal Law of Procrastination. Physics Today 2016;69:1.

[14] Petersen MA, Norgaard LS, Traulsen JM. Pursuing Pleasures of Productivity: University Students' Use of Prescription Stimulants for Enhancement and the Moral Uncertainty of Making Work Fun. Culture, medicine and psychiatry 2015;39:665-679.

[15] CX Tan, RP Ang, RM Klassen,etc. Correlates of academic procrastination and students' grade goals. Current Psychology 2008, 27;27:135-144.:

[16] Rice KG, Richardson CM, Clark D. Perfectionism, procrastination, and psychological distress. Journal of counseling psychology 2012;59:288-302.

[17] Jackman JM, Strober MH. Fear of feedback. Harvard business review 2003;81:101-107, 124.

[18] Umeh K, Omari-Asor L. Emotional vulnerability and coping styles for resolving decisional conflict. The Journal of psychology 2011;145:297-312.

[19] Ariely D, Wertenbroch K. Procrastination, deadlines, and performance: self-control by precommitment. Psychological science 2002;13:219-224.

[20] Paglis LL, Green SG, Bauer TN . Does adviser mentoring add value? A longitudinal study of mentoring and doctoral student outcomes.. Research in Higher Education. 2006;47:451:476.

[21] Ramsay JR. Assessment and monitoring of treatment response in adult ADHD patients: current perspectives. Neuropsychiatric disease and treatment 2017;13:221-232.

[22] Tuckman BW. Relations of academic procrastination, rationalizations, and performance in a web course with deadlines. Psychological reports 2005;96:1015-1021.

[23] Johnson PE, Jr., Perrin CJ, Salo A, Deschaine E, Johnson B. Use of an explicit rule decreases procrastination in university students. Journal of applied behavior analysis 2016;49:346-358.

[24] Kocoglu D, Emiroglu ON. The Impact of Comprehensive School Nursing Services on Students' Academic Performance. Journal of caring sciences 2017;6:5-17.

[25] Gupta N, Singh VK . Effect of Stress on Working Women Life. International Multidisciplinary Research journal 2016;4:71-79. 